International Journal of Health Sciences
Available online at http://sciencescholar.us/journal/index.php/ijhs
Vol. 3 No. 2, August 2019, pages: $21 \sim 27$
e-ISSN: 2550-696X, p-ISSN: 2550-6978
https://doi.org/10.29332/ijhs.v3n2.289

\title{
Relationship between Behavioral Intention and Alcohol Consumption
}

\author{
CrossMark \\ Sulma Alina Hing Ruano a , Ailen Galano Estevez ${ }^{\text {b }}$, Dilka Leyva Rodriguez ${ }^{\text {c }}$ \\ Article history: Received 27 December 2018, Accepted: 30 April 2019, Published: 6 June 2019
}

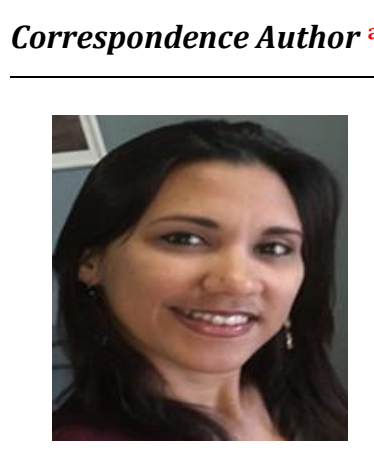

Keywords

alcohol consumption; attitudes;

behavioral control;

behavioral intention; subjective norms;

\begin{abstract}
In recent years, one of the most significant theories to understand the intention of alcohol consumption is the Theory of Planned Behavior that underlies the Theory of Reasoned Action. It has considered necessary to conduct a literature review with the following objective: Determine the relationship between Behavioral Intention and Alcohol Consumption. Because of the theoretical review carried out, it was possible to identify that numerous authors highlight behavioral intention as a subjective probability in which a behavior is connected to an action. The theory postulates have closely linked to behavior, that intention is the function of two basic determinants; one of a personal nature and the other has to do with social influence. The personal factor is the positive or negative evaluation about executing a behavior, this has called "attitude. The social factor is the perception of the social pressure of each individual in order to carry out or not carry out a certain behavior, this factor has called "subjective norm. It has concluded, therefore, that the modification of behavioral intentions could be an option for the development of intervention strategies that have the purpose of preventing the consumption of alcohol.
\end{abstract}

e-ISSN: 2550-696X, p-ISSN: 2550-6978 ${ }^{\circledR}$ Copyright 2019. The Author. SS Journals Published by Universidad Técnica de Manabí. This is an open-access article under the CC BY-SA 4.0 license (https://creativecommons.org/licenses/by-sa/4.0/) All rights reserved.

\section{Contents}

Abstract

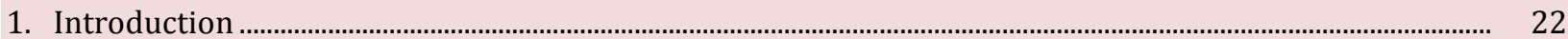

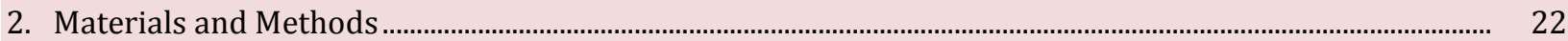

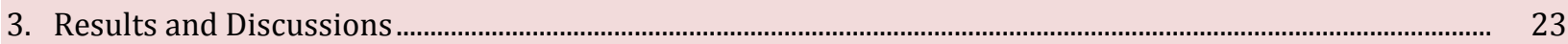

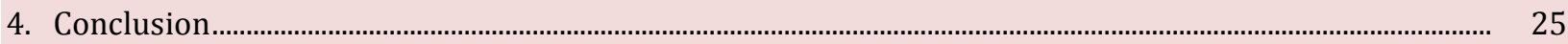

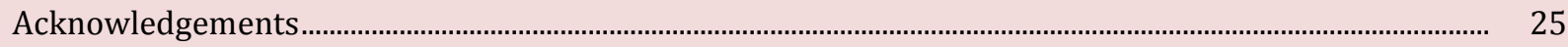

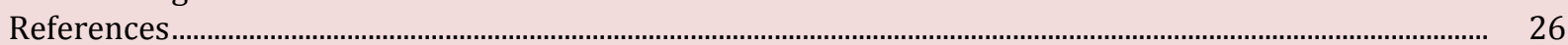

a Degree in psychology, MINET, Universidad de Oriente, Santiago de Cuba, Cuba

b MsC. Instructor Teacher of the Universidad de Oriente, Santiago de Cuba, Cuba

c Specialist in Psychometry of the Universidad de Oriente, Santiago de Cuba, Cuba 


\section{Introduction}

The origin of relations between alcohol, man and society, is lost over time, to give way to a current problem that does not respect culture, economy or religious creed. Data provided by the WHO reveals that alcoholism has become the first risk factor among young people, with 55000 deaths per year of people between 15 and 29 years of age, mainly due to traffic accidents caused by that consumption (Gárciga et al., 2015). On the other hand, the decrease in the age of onset has resulted in a higher prevalence of some health problems both physically and mentally.

Cuba does not remain oblivious to this health problem, $45.2 \%$ of the population consumes alcoholic beverages with a prevalence rate of $6.6 \%$. In the last five years, it has grown significantly (Gonzales \& Donaine, 2012). A recent study by the Pan American Health Organization (PAHO), the who regional office for the Americas, includes Cuba among the countries that have the highest mortality rates due to causes attributable to alcohol, which reflects the harmful patterns of Consumption (National Medical Sciences Information Center, 2017).

Data provided by the National Survey of Risk Factors applied in Cuba in 2013, shows that in the case of alcohol $67.4 \%$ of the population consumes it habitually, $85.1 \%$ is considered a social drinker, $7.1 \%$ risk drinker, 5.1\% harmful drinker and 2.7\% alcohol dependent. These data show that alcohol is one of the most widely used addictive substances in Cuba.

Therefore, it is becoming increasingly necessary to search for programs aimed at preventing or reducing the wide social problem that results from alcohol consumption. Precisely, in recent years it has been suggested that the modification of behavioral intentions from the variables that favor consumption are a possible way to prevent alcohol consumption, based on the Theory of Planned Behavior. However, there are still insufficient studies that exist on this theory, for which it was considered necessary to conduct a literature review with the objective following: Determine the relationship between Behavioral Intention and Alcohol Consumption (Estevez et al., 2018; 2019).

This article is of great importance and practical use for researchers since it constitutes a theoretical foundation that integrates and systematizes concepts, indicators, and variables that make it possible to understand the importance acquired by behavioral intentions in the prevention of alcohol consumption.

First, it is important to point out that the behavioral intention category has been conceptualized by different authors, among which (Warshaw \& Davis, 1985), stand out, who defined it as the degree to which people have conscious plans to perform or not conduct. Meanwhile, more recent authors such as Bermúdez \& Contreras (2008), emphasize that the intention represents the motivational basis that leads the individual to make the decision to undertake a certain course of action. It is considered to be the immediate antecedent of the behavior.

Regarding the phenomenon of drugs, the individual's intention towards alcohol consumption is determined by a set of beliefs that the person has regarding the effects of these substances and the positive or negative evaluation made towards each of these consequences. This evaluation is the effective component of the attitude, determining the motivation and strength of the intention of the consumption of alcohol.

\section{Materials and Methods}

Research methods used to locate the relevant studies: A review of the bibliographic databases was carried out, where the topic associated with the relationship between behavioral intention and alcohol consumption is addressed, taking into account the references of all the publications relevant on the subject for 10 years to date, and documents are written in Spanish and English (these articles can be reviewed in the Bibliography).

Analysis of documents: The analysis of documents is the process by which the most outstanding information contained in a given information source is determined and extracted, which is separated into its constituent elements based on a specific organization. 
The analysis carried out involved the following phases: Familiarization with the content of the document or series of documents, Preliminary classification of documents based on their content and organizational criteria (first evaluation), Selection and extraction of the most relevant or outstanding information, in order to eliminate all that is not necessary, and thus reduce the volume of materials to be handled, Verification of the concepts or data in individual extracts (second evaluation).

Synthesis of the information

It is the process of condensation and distillation of the information analyzed from one or more sources, which is now presented in a new format or structure and with an interpretative or evaluative point of view, The synthesis consisted of the following phases: Ordering and combination of information, Comparative evaluation of the different extracts or data (third evaluation), Condensation of the information in a structure and more affordable way and in accordance with the objectives and sources worked.

\section{Results and Discussions}

The planned theory of behavior was developed by Azjen \& Madden (1991), given the limitations of the Reasoned Action, theory to explain those behaviors over which it has incomplete volitional control and also for those that occur in contexts specific (Guzmán \& García, 2014). The Theory of Planned Behavior incorporates original elements of the Theory of Reasoned Action but also introduces the variable of Perceived Behavior Control, defined as the difficulty or perceived ease of developing a behavior.

According to the Theory of Planned Behavior, people act in accordance with their intentions and Perceived Behavioral Control over behavior, while intentions are influenced by Attitude towards behavior, by the subjective norm and by the perception of behavioral control. According to this theory, intentions and behaviors are a function of three basic determinants, one of a personal nature, another that reflects social influence, and the last one that deals with control issues (Terrero, 2014).

The personal factor is the positive or negative evaluation about executing a behavior, this is called "attitude", which is linked to those results or consequences that an individual can expect from the execution of the behavior.

The social factor is the perception of the social pressure of each individual in order to carry out or not carry out a certain behavior, this factor is called "subjective norm", which is linked to the beliefs of significant persons. So, generally speaking, when a person evaluates positively and when he believes that it is important for others to carry out certain behavior, he should do so.

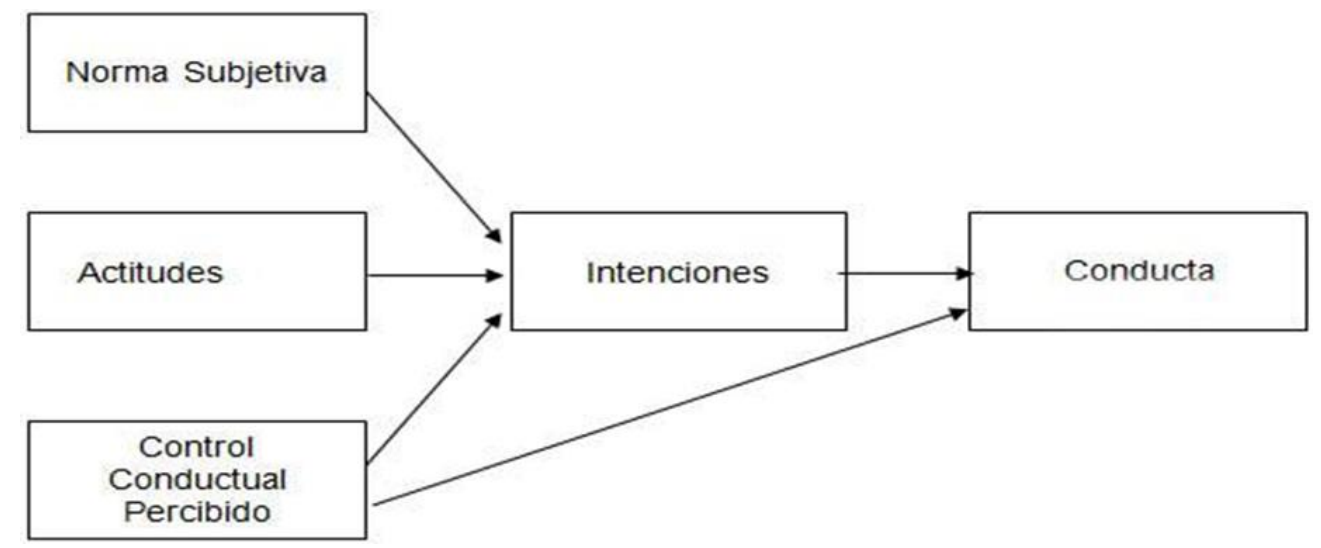

Figure 1. Graphical representation of the theory of planned conduct

Consumption is widely spread and accepted in its reference groups, will influence the intention (Ajzen, 1991), also mentions that internal factors have been taken into account in relation to the execution of behavior, referring to individual differences. Differences between people about beliefs about control or lack of control to perform a behavior. Information, skills, and abilities: it seems that the success of carrying out behavior is

Ruano, S. A. H., Estevez, A. G., \& Rodriguez, D. L. (2019). Relationship between behavioral intention and alcohol consumption. International Journal of Health Sciences, 3(2), 21-27. https://doi.org/10.29332/ijhs.v3n2.289 
contingent in the presence of information, skills, and abilities required, which explains the relationship between intention and skills with respect to current behavior.

Ajzen, then, tells us that while we mobilize after intentions, several internal factors influence the good and satisfactory execution of intentional behavior. It can be relatively easy to gain control over those factors to the extent that we acquire the information or skills necessary to engage in a behavior. Other factors such as intense emotions are more difficult to neutralize, in any way, or whatever the nature of the internal factor, will influence the control over the purpose of the behavior.

Even a person's control over the goal of behavior also depends on factors of an external or situational nature such as time and opportunity, which refers to the absence of appropriate circumstances or the necessary time, which makes people change your intentions. Many times people's intentions are usually firm but they fail because circumstances prevent the behavior from taking place. On the other hand, another factor that intervenes is the dependence of others; When carrying out a behavior depends on other people, there is the potential of not having control over the achievement of the behavior.

The Theory of Planned Behavior maintains that consuming substances such as alcohol is directly related to the intention to consume it, which involves the 3 aforementioned components, the attitude of the person before the consumption of alcohol, that is, the relevant beliefs about alcohol. the consequence of the consumption and the effective value that the individual attributes to such consequences; their normative beliefs and perceived behavioral control.

The attitude towards a behavior has determined by the beliefs that unite it with the results and the evaluation of said results (Guzmán \& Garcia, 2014). There is general agreement that the Attitude represents a summary evaluation of a psychological purpose subject to attributive dimensions such as good-bad, harmfulbeneficial, pleasant, and sympathetic-unfriendly.

Each belief associates the purpose with a certain quality, and the total attitude of the person towards a purpose is determined by the subjective values of the qualities of the purposes in interaction with the strength of the associations.

However, these beliefs can be reinforced in young people if they have previous experimentation with consumption, which will lead them to have a more favorable attitude, based not only on individual beliefs but also on the experience of drug use, which can enhance the positive attitude towards consumption (Peña, 2017).

This attitude toward a behavior is governed by the beliefs that are given by the results obtained and the evaluation. And as for the consumption of alcohol is determined mainly by the evaluation of the consequences that the consumption generates in the individual; The main problem is that the beliefs are being reinforced in the young people either in the family or in the social relationships they have; and this, in turn, will be determined by the experience they have of consuming alcohol, which can boost their consumption in a positive way (Peña, 2017).

The subjective norm is normative reasoning that highlights the social pressure perceived by the person who is going to carry out the conduct towards the execution or not of said behavior. It shows us the result of the evaluation that the person makes of whether the significant others (family, friends, etc.) want him or her to perform that behavior and the motivation to please them. Assuming an analogy of the expectation-value model of the Attitude, it is assumed that the Subjective Rule is determined by the total set of Normative Beliefs available or accessible with respect to the expectations of important referents towards that behavior, that is, the subjective norm it is determined by two components: by the perception that other important people for the subject approve, think, hope and desire their behavior (normative beliefs); and the motivation of the subject itself to accommodate the expectations or desires of those people (motivation to adjust). If the adolescent perceives that his friends expect or think that he uses drugs, his decision will tend to lean toward consumption. In relation to this, the belief (right or wrong) that $\mathrm{n}$ to consume or not drugs.

Behavioral control is nothing more than a personal belief in the ability to control existing difficulties in performing a behavior. That is, the young person's perception of himself as able or not to use drugs or face social pressure to do so.

A study was carried out by Torres (2010), whose objective was to identify the attitudes, the behavioral intention of consumption and the consumption of alcohol and cocaine in young people from a town in the city of Nuevo Laredo, Tamaulipas. On the other hand, Edith Carolina Hernández (2017), in a study conducted to see the relationship of the variables of the theory in relation to behavioral intention in children of five and 
sixth grade to test alcoholic beverages, according to the author children in study were able to report their intention of consumption in a manner consistent with the behavior.

In Monterrey, a study was carried out based on the Theory of Planned Behavior (Terrero, 2014), that demonstrated the relationship between attitude and intention towards alcohol consumption. Many have been the investigations supported in this theory (TCP), not only from the intention of the consumption of alcoholic beverages but from diverse edges and all demonstrate the effectiveness and the great contribution of the same one to the study of the human behavior, it offers a complete model of research that allows to evaluate determining factors in behavior such as beliefs, attitudes, subjective norms, motivation and intention towards the performance of a behavior.

\section{Conclusion}

The research supported by the Theory of Planned Conduct has been different, not only from the intention of the consumption of alcoholic beverages but from diverse edges and all demonstrate the effectiveness and great contribution of the same to the study of human behavior, offering a model complete of investigation that allows evaluating determining factors in the behavior as they are the beliefs, the attitudes, the subjective norms, the motivation and the intention towards the accomplishment of a conduct. It is concluded, therefore, that the modification of behavioral intentions could be an option for the development of intervention strategies that have the purpose of preventing the consumption of alcohol.

\section{Acknowledgments}

Special thanks to the University for supporting the research carried out.

Ruano, S. A. H., Estevez, A. G., \& Rodriguez, D. L. (2019). Relationship between behavioral intention and alcohol consumption. International Journal of Health Sciences, 3(2), 21-27. https://doi.org/10.29332/ijhs.v3n2.289 


\section{References}

Ajzen, I. (1991). The theory of planned behavior. Organizational behavior and human decision processes, 50(2), 179-211. https://doi.org/10.1016/0749-5978(91)90020-T

Ajzen, I., \& Driver, B. L. (1991). Prediction of leisure participation from behavioral, normative, and control beliefs: An application of the theory of planned behavior. Leisure sciences, 13(3), 185-204. https://doi.org/10.1080/01490409109513137

Bermúdez, J. and Contreras, A. (2008). Psychosocial predictors of adolescent tobacco use: extensions of the theory of planned behavior. Journal of Psychopathology and Clinical Psychology, 13(3), 165-186.

Estevez, AG, Roche, JRF, Espinosa, AHR, \& Rodríguez, DL (2018). Social skills training program to prevent alcohol in university students. International Journal of Health Sciences, 2 (3), 4354. https://doi.org/10.29332/ijhs.v2n3.216

Estevez, AG, Roche, JRF, Saborit, AR, Espinosa, AHR, \& Rodriguez, DL (2019). Relationship between social skills and alcohol. International Journal of Health Sciences , 3 (1), 1-8. https://doi.org/10.29332/ijhs.v3n1.244

Gárciga Ortega, O., Torres, C. S., \& Jorge, R. R. (2015). Consumption of legal drugs and lifestyle in medical students. Revista Cubana de Salud Pública, 41(1), 4-17.

Gonzales, R. \& Donaine, I. (2012). The rehabilitated path of the addicted patient. La Habana, Editorial José Marti, 2(2), 45-150.

Guzmán F. \& García B. (2014). Attitude, subjective norm and behavioral control as predictors of drug use in young people in the marginal zone of northern Mexico. Northern border; 26 (51), 53-74. Available at: http://www.scielo.org.mx/

Hernández Chávez, EC, Salazar Garza, ML, Vacio Muro, MDL Á., \& Rodríguez-Kuri, SE (2017). Instrument to use alcoholic beverages based on the Theory of Planned Behavior. Universitas Psychologica , 16 (2), 80-89.

Peña, S., Mäkelä, P., Valdivia, G., Helakorpi, S., Markkula, N., Margozzini, P., \& Koskinen, S. (2017). Socioeconomic inequalities in alcohol consumption in Chile and Finland. Drug and alcohol dependence, 173, 2430. https://doi.org/10.1016/j.drugalcdep.2016.12.014

Terrero, J. (2014). Attitudes and intention towards the consumption of alcohol and tobacco in nursing students. Master's Thesis. Universidad Autónoma de Nuevo León July 2014.

Torres J. (2010), Attitudes, behavioral intention of alcohol and cocaine use among young people. Autonomous University of Nuevo León.

Warshaw, P. R., \& Davis, F. D. (1985). Disentangling behavioral intention and behavioral expectation. Journal of experimental social psychology, 21(3), 213-228. https://doi.org/10.1016/0022-1031(85)90017-4 


\section{Biography of Authors}

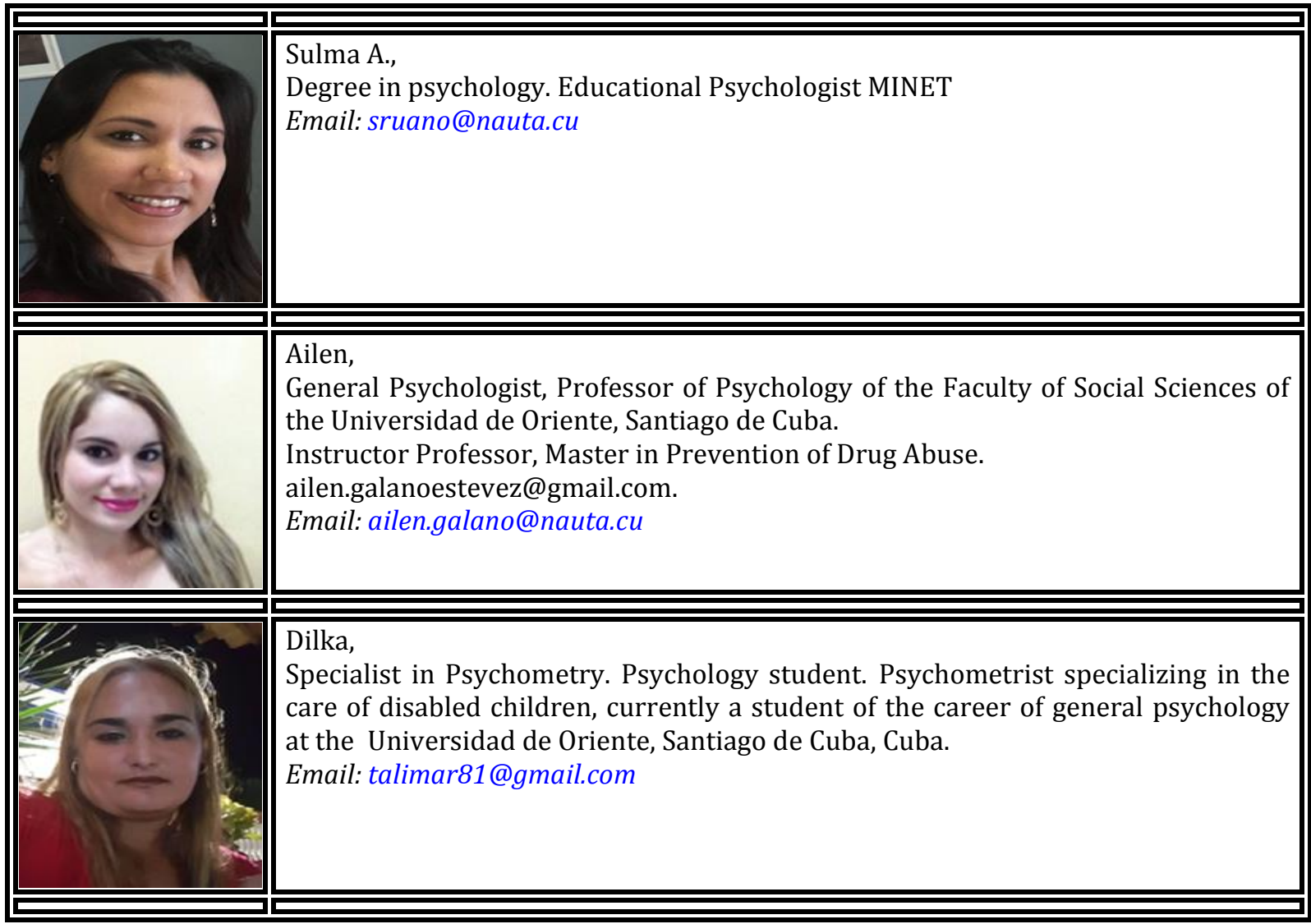

Ruano, S. A. H., Estevez, A. G., \& Rodriguez, D. L. (2019). Relationship between behavioral intention and alcohol consumption. International Journal of Health Sciences, 3(2), 21-27. https://doi.org/10.29332/ijhs.v3n2.289 